\title{
Morphometric analysis of nuclei in epithelial structures from normal and neoplastic endometrium: a study using the Isaacs cell sampler and Endoscann instruments
}

\author{
ELSA SKAARLAND \\ From the Gade Institute, Department of Pathology, University of Bergen, N-5016 Haukeland Hospital, \\ Norway
}

SUMMARY Morphometric analysis of nuclear area and shape in epithelial cells from cytological specimens from 35 patients with normal endometrium and from 20 patients with moderately or well differentiated endometrial adenocarcinoma was performed. The mean nuclear area in malignant cells was significantly higher than in normal epithelial cells. The range of the mean values from the normal cases, however, included $70 \%$ of the malignant values. Furthermore, individual cell groups in a normal cell population often gave values well within the malignant range. The greatest distinction between normal and malignant cases was obtained using a cut off mean value of $45 \mu \mathrm{m}^{2}$. With this as the sole criterion $17 \%$ of reports would have been false positives and $25 \%$ false negatives.

Endometrial cytology has been in routine use in our region (Western Norway) since $1979-80$, both in the gynaecological department at the university hospital and in gynaecological practice in the region. Accuracy tests on sampler material have shown that it may be as reliable as curettings and that cytological evaluation can be as accurate as histology in malignant cases, ${ }^{1-11}$ although there are reports of disappointing results. ${ }^{12}$

It is commonly accepted that epithelial cell nuclei are smaller in normal than in malignant conditions of the endometrium. ${ }^{13-15}$ Evaluation of this sampler material, however, showed unexpected variation in nuclear appearance due mainly to variation in nuclear size. Smears in which the architecture of the glands was obviously normal on occasion showed pronounced nuclear enlargement, while smears with obvious malignant structure were often, on closer investigation, composed of almost normal looking cells. This study describes the variation in nuclear area and shape of epithelial cells seen in endometrial samples from a series of 35 normal and 20 malignant cases.

Accepted for publication 17 January 1985

\section{Material and methods}

Thirty five cases with normal endometrial histology and 20 cases showing histologically moderately or well differentiated adenocarcinoma were studied. They were taken from a previous series of 400 patients in whom endometrial cell sampling using either the Isaacs cell sampler ${ }^{6}$ or the Endoscann instrument " had been followed by curettage. Consecutive cases with the requisite diagnosis were selected from our files (Table 1). Two histopathologists had agreed on the histological diagnosis in each case.

When introduced into the uterine cavity both sampler instruments produced tissue fragments of surface epithelium, underlying stroma, and variable numbers of glands in normal cases. In malignant cases the material consisted of tumour tissue and variable amounts of the same material as in normal cases. For histological analysis the curettings had been fixed in $4 \%$ neutral buffered formaldehyde and stained with haematoxylin and eosin. The cytological material was smeared on to four glass slides, fixed in $96 \%$ alcohol, and stained by the Papanicolaou method. Only one of the four slides was used for measurement; the one used was the 
Table 1 Mean nuclear area $(M N A)( \pm S D)$ in epithelial cells from 35 cytological samples from normal endometrium and 20 samples from patients with moderately or well differentiated adenocarcinoma of the endometrium

\begin{tabular}{|c|c|c|c|c|c|c|}
\hline \multirow{2}{*}{$\begin{array}{l}\text { Histological diagnosis } \\
\text { (curettings) }\end{array}$} & \multicolumn{3}{|l|}{ Endoscann } & \multicolumn{3}{|l|}{ Isaacs } \\
\hline & No of patients & $M N A$ & Mean age & No of patients & $M N A$ & Mean age \\
\hline $\begin{array}{l}\text { Proliferation } \\
\text { Secretion } \\
\text { Atrophy } \\
\text { Normal endometrium } \\
\text { Adenocarcinoma (R) } \\
\text { Adenocarcinoma (D) }\end{array}$ & $\begin{array}{r}5 \\
5 \\
5 \\
15 \\
10 \\
10\end{array}$ & $\begin{array}{l}40 \pm 12 \\
43 \pm 14 \\
38 \pm 9 \\
40 \pm 11 \\
62 \pm 19 \\
67 \pm 14\end{array}$ & $\begin{array}{l}48 \pm 5 \\
44 \pm 5 \\
60 \pm 14 \\
66 \pm 8 \\
66 \pm 8\end{array}$ & $\begin{array}{r}5 \\
5 \\
10 \\
20 \\
10 \\
10\end{array}$ & $\begin{array}{l}42 \pm 10 \\
34 \pm 3 \\
34 \pm 5 \\
36 \pm 7 \\
53 \pm 11 \\
64 \pm 13\end{array}$ & $\begin{array}{l}37 \pm 10 \\
40 \pm 6 \\
63 \pm 9 \\
65 \pm 7 \\
65 \pm 7\end{array}$ \\
\hline
\end{tabular}

$\mathbf{R}=$ random measurement. $\mathbf{D}=$ diagnostic measurement.

first which on screening at $\times 25$ magnification showed abundant material.

Measurements of nuclear area and nuclear shape were performed. The slides were evaluated with a light microscope (Leitz Dialux $20 \mathrm{~EB}$ ) with a tracing device. A cursor with a light diode was placed on a digitising plate (Bit pad One TM Summagraphics
Corporation, Fairfield, Connecticut) and with a drawing tube the light diode was projected on to the slide. The digitising plate was connected to a microcomputer (Commodore computer CBM 4032, Commodore Business Machines, St Clara, California). The nuclear circumference was followed with the light diode and a recording made at $\times 400$

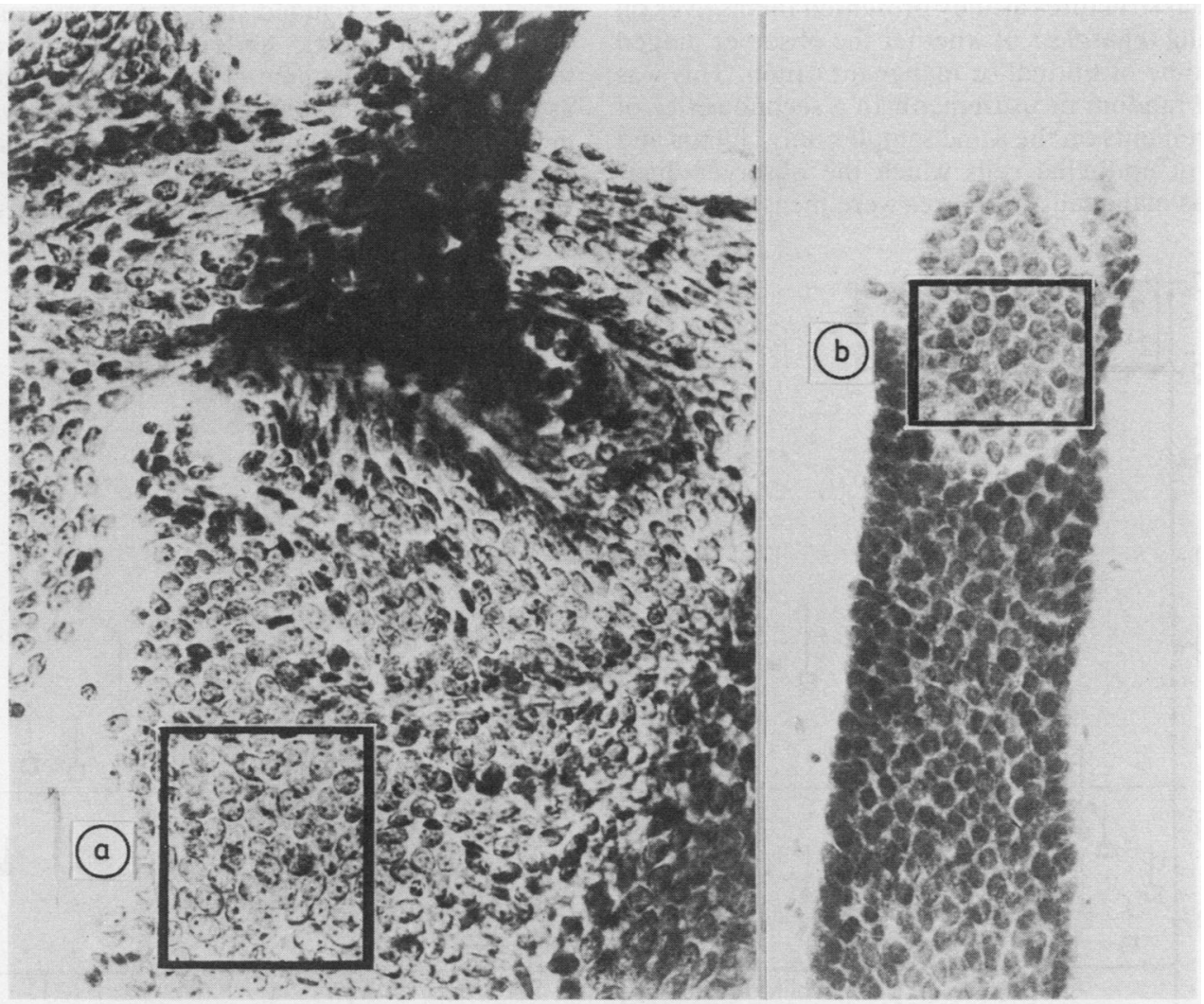

Fig. 1 Photomicrograph of a cytological smear from normal endometrium, $\times 225$. (a) Typical example of a field measured in a superficial epithelial sheet. (b) Example of the monolayer chosen for measurement in glandular structures. 
magnification. A morphometric program (MTS, Medizinish Technische Apparate, Tübingen, West Germany) was used to measure the length of the circumference, the area of the nucleus (in $\mu \mathrm{m}^{2}$ ), and the shape of the nucleus, expressed as the form factor, simultaneously. A circle has the form factor 1.0.

In normal cases consecutive epithelial sheets or glandular structures were measured on routine screening of the slide. Twenty nuclei in each of 10 different epithelial structures were measured. The structures were excluded from measurement only if they did not contain at least 20 well preserved nuclei without artefacts such as stretching, crushing, or air drying. Pyknotic nuclei and mitotic figures were also excluded. Fig. 1 gives typical examples of a measurement field in a sheet of superficial epithelium and the monolayer field chosen for measurement in glandular structures. Measurement was done after optimal focusing of each nucleus.

In malignant samples two different types of recordings were made. One was performed in the same way as in normal samples, measuring nuclei in epithelial structures as they presented themselves on screening regardless of whether the observer judged them to be of normal or malignant origin. This was termed random measurement. In a second series of measurements on the same samples only clumps and sheets of epithelial cells which the observer diagnosed as malignant structures were measured; other

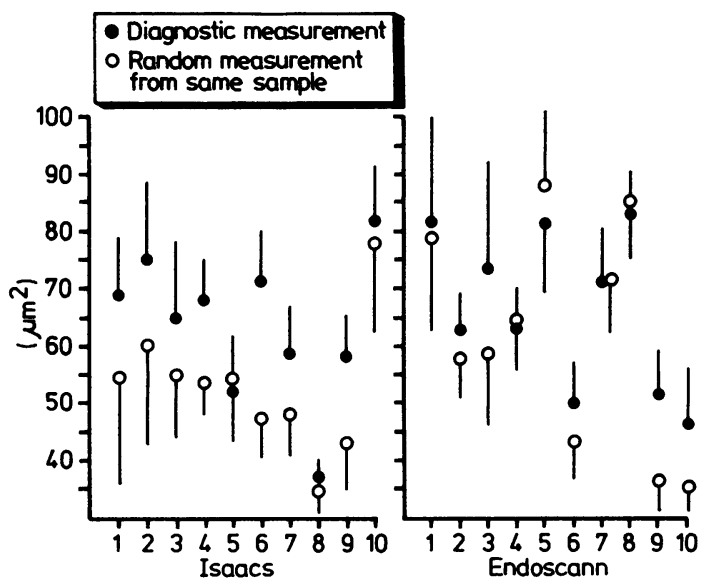

Fig. 2 Comparison between diagnostic and random measurements performed in each of 20 samples from patients with moderately or well differentiated

adenocarcinoma of the endometrium. Vertical lines show standard deviation.

structures were excluded. This type of measurement was termed diagnostic. Criteria for malignancy were the subjective assessment of architectural details such as papillary formations and irregular crowding of more or less well formed glandular formations, quality of the background material, cellular size, nuclear size, nuclear to cytoplasmatic ratio, nuclear staining

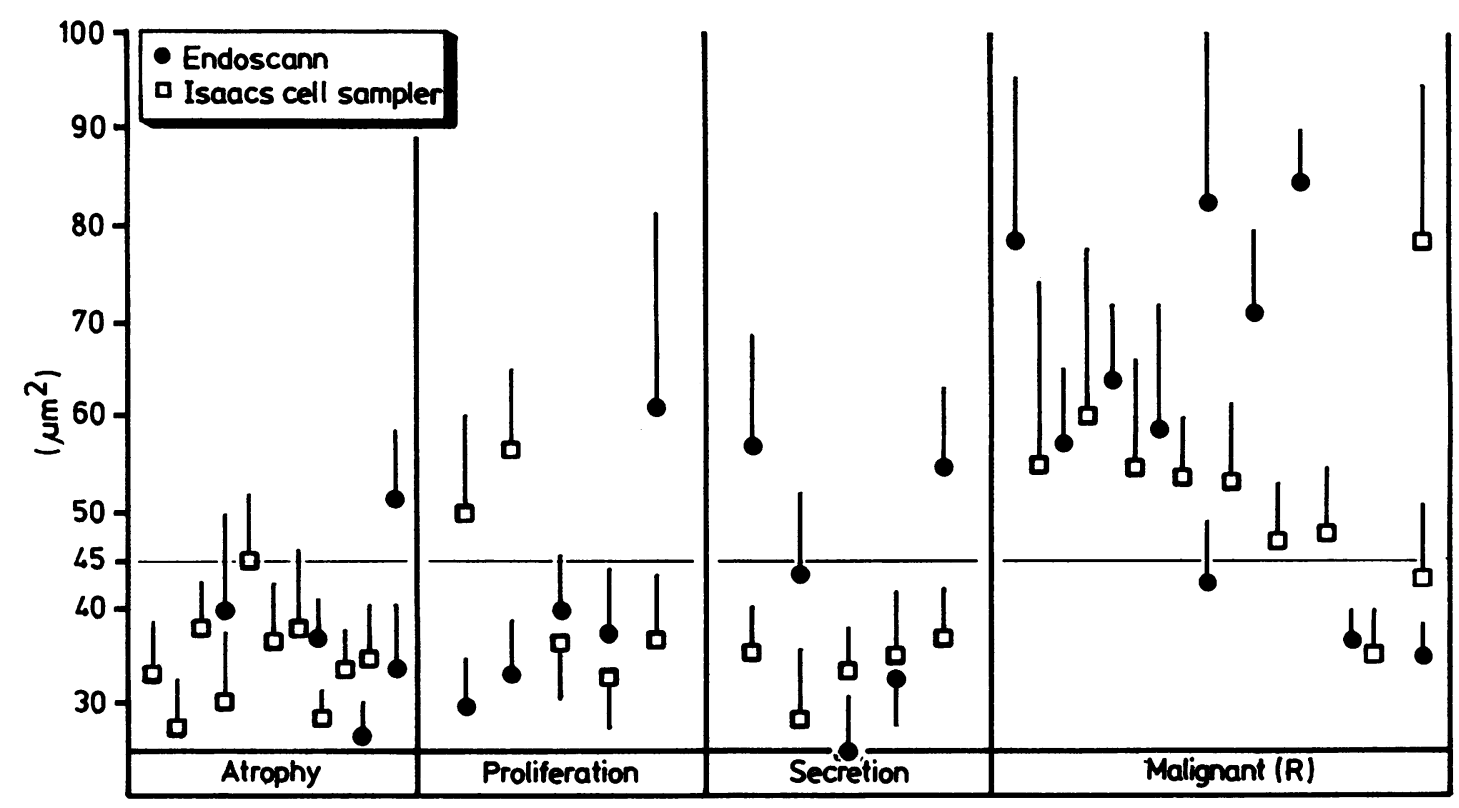

Fig. 3 Mean nuclear area from one sample from each of 55 patients with different endometrial conditions. SD given as vertical lines for each case. 
SD

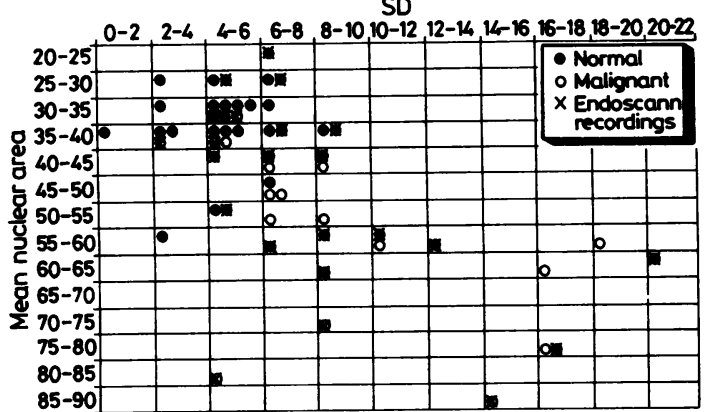

Fig. 4 Mean nuclear area for each of 55 samples related to standard deviation (SD).

properties, and nucleolar abnormalities.

\section{Results}

The mean nuclear area (MNA) in normal epithelial cells did not vary with hormonal state since an almost identical MNA was found in atrophic endometrium and in the proliferative and secretory phases of the normal cycle (Table 1). The MNA was also similar when measured on cells derived from the two samplers. The MNA for all measurements with both instruments for normal endometrium was $38 \pm 9 \mu \mathrm{m}^{2}$. Table 1 also shows that malignant epithelial cells had a similar MNA on random and diagnostic measurement; the observed differences were not significant. There was no significant difference in the results from the Isaacs and the Endoscann instruments. The mean for all the malignant random measurements was $57 \pm 16 \mu \mathrm{m}^{2}$ and for the diagnostic measurements $65 \pm 13 \mu \mathrm{m}^{2}$. The differences in mean between normal material and malignant, $19 \mu \mathrm{m}^{2}$ for random and $27 \mu \mathrm{m}^{2}$ for diagnostic measurement, were both significant ( $t$ test, $p<$ 0.001 for both). Fig. 2 shows that the random measurements lay under the diagnostic in all but five cases. In these five cases the means were similar, the standard deviations overlapping.

Different cut off points were tested: a MNA of $45 \mu^{2}$ (Fig. 3) proved to be the value that discriminated best between normal and malignant conditions $\left(\chi^{2}=18 \cdot 1, p=0.00002\right)$. Only one case with atrophic endometrium showed values over $45 \mu \mathrm{m}^{2}$. Three of 10 cases in proliferation and two of 10 in secretion exceeded this value. In contrast, 15 of 20

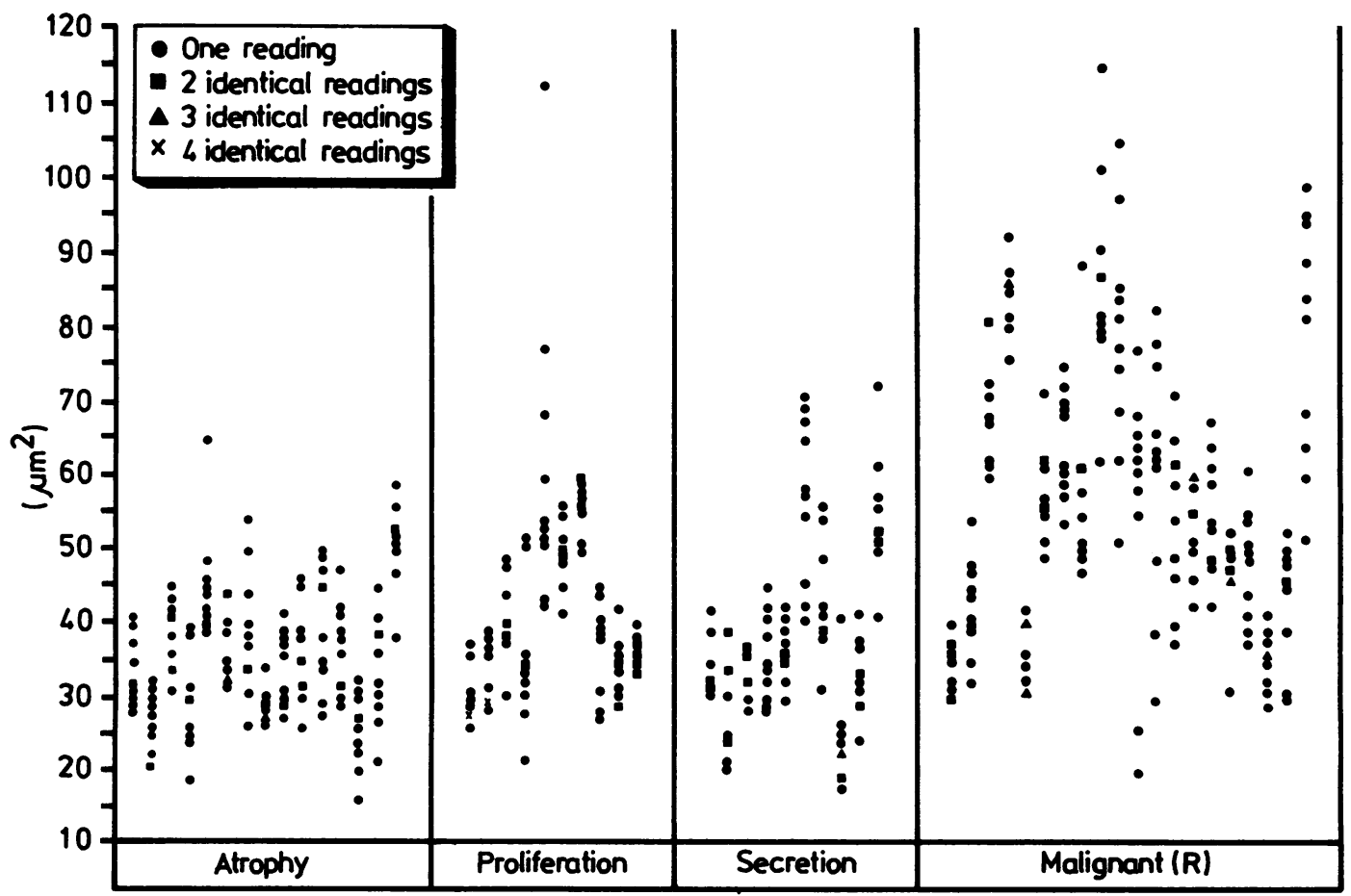

Fig. 5 Mean nuclear area from each cell group from each of 55 samples related to the condition of the endometrium. Each sample is presented as a column of points. Each point represents one or more cell groups. 
Table 2 Mean of variation coefficient in normal endometrium and in moderately or well differentiated adenocarcinoma of the endometrium

\begin{tabular}{lll}
\hline Histological diagnosis (curettings) & Endoscann & Isaacs \\
\hline Proliferation & $17 \pm 4$ & $17 \pm 4$ \\
Secretion & $16 \pm 4$ & $16 \pm 4$ \\
Atrophy & $17 \pm 4$ & $17 \pm 5$ \\
Malignant (R) & $19 \pm 5$ & $21 \pm 5$ \\
Malignant (D) & $21 \pm 6$ & $20 \pm 5$ \\
\hline
\end{tabular}

$\mathbf{R}=$ random measurement; $\mathbf{D}=$ diagnostic measurement.

malignant cases were above and five below. If values over $45 \mu \mathrm{m}^{2}$ were considered indicative of malignancy there would have been six false positive (17\%) and five false negative reports (25\%).

Fig. 4 shows the relation between the MNA and its standard deviation in each of the 55 cases measured. For cases with MNA values below $45 \mu \mathrm{m}^{2}$ the standard deviation of the mean did not exceed 10 irrespective of whether the cases were normal or malignant. In contrast, when the MNA was over $45 \mu^{2}$ the standard deviation in about half the cases was over 10, again irrespective of whether the cases were normal or malignant. Fig 5 shows the range of MNA values from each of the cell groups measured from each of 55 samples related to the condition of the endometrium. The scatter indicates great overlap in mean value in normal and malignant conditions. Only $17 \%$ of the MNA values obtained from malignant cases had readings above the upper level of normal conditions. Fig. 5 also indicates a wide range of MNA values both in the various normal conditions and in malignant cases. Further, an individual case with normal endometrium may show MNA values with a small range, while others show a wide range. The same holds for malignant cases. Cases with almost identical MNA values were found in malignant and atrophic endometrium.

Each of the points in Fig. 5 is the MNA from 20 nuclei. The mean of the variation coefficient for all these readings is related to the condition of the endometrium in Table 2. This variation, in contrast to that in Fig. 5, is an expression of the heterogenicity of the nuclei in the local cell population in a given endometrial condition. The figures show no difference between measurements with the two samplers: similarity in readings in normal conditions with slightly higher values in malignancy, irrespective of the type of reading, random or diagnostic. Thus the groups can probably be regarded as comparable.

In normal conditions the nuclei were round or nearly round (range $0 \cdot 84-1 \cdot 0$ ). The range for malignant recordings was $0 \cdot 65-1 \cdot 0$, but the mean value for recordings both in normal and malignant conditions was $>0 \cdot 9$.

\section{Discussion}

Modern cytological sampler material from the endometrium is a challenge to the cytologist in many ways. Firstly, one is unfamiliar with the type of material. The Isaacs cell sampler and Endoscann used in this study produce quite large tissue fragments in addition to sheets, small clumps, and single cells. Secondly, few systematic descriptions of the appearance of the cytological material from these samplers have been published and the diagnostic criteria have not been clearly defined. Reports that the mean nuclear area is greater in malignant epithelium, ${ }^{13-15}$ confirmed in this study, leaves one with the impression that malignant epithelium has larger nuclei than normal epithelium. This may be one explanation for the consistently, but not significantly, higher values for diagnostic compared with random readings found in the present study. Further, the general concept of variation in nuclear size and shape in malignant tissue leads one to expect a greater variability in carcinoma cases than in normal conditions. ${ }^{16}$ The present work shows that neither of these concepts holds in practice for well or moderately differentiated adenocarcinoma of the endometrium.

The combination of nuclear size, range in nuclear size, and shape of the nuclei is also of little help, since normal and malignant cases vary in the same way in these respects. A tendency to high MNA values combined with high standard deviations was seen in some of the malignant cases but was also found in benign samples. The low MNA values seen in some malignant cases are noteworthy. It is unlikely that the values represent measurement of normal structures in the samples, since curettings from these showed a clear predominance of tumour tissue.

From these results it follows that morphometric analysis of sampler material with a focus on nuclear size and shape cannot be used as a screening method for malignancy in the endometrium. It also follows that in subjective assessment of the material in routine diagnostic work one must not pay too much attention to nuclear size, but rather take other criteria into consideration, especially the architecture of the tissue and the quality of the background. As sampler material comes into more general use, the problems it presents will become increasingly important to both cytotechnologists and cytopathologists. They should be aware of the wide range of nuclear appearances in normal conditions of the endometrium. At the same time full awareness that well and moderately differentiated endometrial carcinomas may consist of cells in which the nuclei do not differ in size or shape from nuclei in normal cells is essential. 
I am grateful to Amanuensis dr. med. Christensen for introducing me to the field of morphometry and for his valuable advice during the study. Professor dr. med. F Hartveit is thanked for help in preparing the manuscript. E Lehmann, $M D$, is thanked for reviewing the results and giving advice in choice of statistical methods. The histological evaluation was performed by Amanuensis dr. med. J Christensen, and Dosent dr. med. Andreas Myking.

\section{References}

' Gravlee LC Jr. Jet-irrigation method for the diagnosis of endometrial adenocarcinoma. Obstet Gynecol 1969; 34:168-73.

${ }^{2}$ So-Bosita JL, Lebherz TB, Blair OM. Endometrial jet washer. Obstet Gynecol 1970;36:287-93.

${ }^{3}$ Underwood PG, Kellett MP, McKee EE, Clark A. The Gravlee washer. Can it replace the diagnostic curettage? Am J Obstet Gynecol 1973;117:201-9.

4 Vuopala S. Diagnostic accuracy and clinical applicability of cytological and histological methods for investigating endometrial carcinoma. Acta Obstet Gynaecol Scand 1977; suppl 70.

${ }^{5}$ Segadal E, Iversen OE, Ulstein M. Comparison of cytological 'jet-wash' specimens and histology in endometrial carcinoma. J Clin Pathol 1980;33:688-90.

- Segadal E, Iversen OE. The Isaacs cell sampler-an alternative to curettage. Br Med J 1980;281:364-5.
${ }^{7}$ Niklasson O, Johansson R, Stormby N. Screening of endometrial carcinoma by jet wash and endouterine aspiration cytology. Acta Obstet Gynaecol Scand 1981;60:125-9.

${ }^{8}$ Ellice RM, Morse AR, Andersen MC. Aspiration cytology versus histology in the assessment of the endometrium of women attending a menopause clinic. Br J Obstet Gynaecol 1981;88:421-5.

' Barbaro CA, Fortune DW, Bodey AS, Hennessy E. Uterine lavage in the diagnosis of endometrial malignancy and its precursors. Acta Cytol 1982;26:135-40.

${ }^{10}$ Farree J, Bernard P, Besancon D, Siebert S. A five-year experience with intrauterine washing cytology. Acta Cytol 1982;26:623-9.

" Segadal E, Iversen OE. Endoscann, a new endometrial cell sampler. Br J Obstet Gynaecol 1983;90:266-71.

${ }^{12}$ Studd JWW, Thom MH, Dische F, Driver M, Wade-Evans T, Williams $D$. Value of cytology for detecting endometrial abnormalities in climacteric women receiving hormone replacement therapy. Br Med J 1979;i:1575-7.

${ }^{13}$ Boschann HW. Symposium on techniques for endometrial cytological examination. Acta Cytol 1958;2:586.

14 Reagan JD, Ng ABP. The cells of endometrial carcinoma. Baltimore, USA: Williams and Wilkins Company, 1965.

is $\mathrm{Ng}$ ABP. The cellular detection of endometrial carcinoma and its precursors. Gynecol Oncol 1974;2:162-79.

16 Koss LG. Diagnostic cytology and its histopathological basis. 3rd ed. Philadelphia: JB Lippincott Company, 1979:73.

Requests for reprints to: Dr Elsa Skaarland, The Gade Institute, Department of Pathology, University of Bergen, N-5016 Haukeland Hospital, Norway. 